\title{
High-resolution petrographic evidence confirming detrital and biogenic magnetites as remanence carriers for Zongpu carbonates in the Gamba area, South Tibet
}

Qian Zhao' $^{1}$ Baochun Huang ${ }^{*}$, Zhiyu Yi², Pengfei Xue ${ }^{1}$

${ }^{1}$ Key Laboratory of Orogenic Belt and Crustal Evolution, Ministry of Education, School of Earth and Space Sciences, Peking University, Beijing, China

${ }^{2}$ Planetary Environmental and Astrobiological Research Laboratory (PEARL), School of Atmospheric Sciences, Sun Yat-sen University, Zhuhai, China

* Correspondence:

7 Baochun Huang

8 bchuang@pku.edu.cn

Keywords: Magnetic extraction, Carbonates, Paleomagnetism, Tethyan Himalaya, Paleocene

\section{Abstract}

Paleocene carbonates from the Gamba area of South Tibet provide the largest paleomagnetic dataset for constraining the paleogeography of the India-Asia collision in the early stage. The characteristic remanences (ChRMs) obtained from this unit were, however, argued for a chemical remagnetization via orogenic fluids. This study carries out a high-resolution petrographic study on the Paleocene carbonates from Gamba aiming to test the nature of the ChRMs. Electron microscopic observation on magnetic extracts identified a large amount of detrital magnetite that are multi- to single domain in sizes and biogenic magnetite in nanoscale. Minor framboidal iron oxides were also identified, which were previously interpreted as authigenic magnetite that substitutes pyrite. However, our scanning and transmission electron microscopic (SEM/TEM) observations, along with optical microscope and Raman spectrum investigations further suggest that these magnetic minerals are pigmentary hematite and goethite that are incapable of carrying a stable primary magnetization. We therefore argue that the ChRMs of the limestones from the Zongpu Formation in the Gamba area are carried by detrital and biogenic magnetites rather than authigenic magnetite. The paleomagnetic data from the Gamba area are interpreted as primary origin and can thus be used for tectonic reconstructions. We emphasize that magnetic extraction, integrated with advanced mineralogic studies (e.g., electron backscatter diffraction and electron diffraction) are effective approaches for investigating the origin of magnetic carriers in carbonate rocks.

\section{Introduction}

Consecutive indentation of India into continental Asia resulted in a rapid uplift of the Tibetan Plateau that has profoundly changed the climatic pattern and topography of Asia since the Cenozoic era (Yin and Harrison, 2000; Jagoutz et al., 2016). The timing and position of the initial collision between India and Asia remain highly debated (e.g., Ding et al., 2005; Leech et al., 2005; Aitchison 
et al., 2007; Ali and Aitchison, 2008; Najman et al., 2010; Yi et al., 2011; van Hinsbergen et al., 2012; Hu et al., 2016; An et al., 2021). On the paleolatitudinal comparison based on reliable paleomagnetic poles, paleomagnetism provides a direct constrain on timing and locus for the initial collision between India and Asia (e.g., Dupont-Nivet et al., 2010; Najman et al., 2010; Yi et al., 2011, 2021)

The Indian plate was subjected to rapid northward motion toward Asia during the Cretaceous and Paleocene (Patriat and Achache, 1984; Yin and Harrison, 2000; van Hinsbergen et al., 2011). The kinematics of the northern margin of India can be constrained by the Cretaceous and Paleogene paleomagnetic data obtained from the Tethyan Himalaya (Besse et al., 1984; Patzelt et al., 1996; Tong et al., 2008; Yi et al., 2011; Yang et al., 2015, 2019; Ma et al., 2016; Meng et al., 2019, 2020; Y. Zhang et al., 2019; Yuan et al., 2020). For the lack of contemporary volcanic rocks, the Late Cretaceous to Paleocene sedimentary rocks from the Tethyan Himalaya are especially crucial for reconstructing the overall process of the India-Asia collision. Several paleomagnetic poles were reported from the marine sediments of the Tethyan Himalaya with the Late Cretaceous to Paleocene in ages (Besse et al., 1984; Patzelt et al., 1996; Tong et al., 2008; Yi et al., 2011; Ma et al., 2016; Yang et al., 2019; Meng et al., 2020; Yuan et al., 2020). In the light of these poles, a variety of paleogeographic reconstructions were established with small (Besse et al., 1984; Tong et al., 2008), moderate (Yi et al., 2011), and enlarged (Meng et al., 2020) Greater India or hypothesized oceanic basins, namely, "Greater India Basin" (van Hinsbergen et al., 2012) or "North India Sea" (Yuan et al., 2020).

A continuously outcropped marine sedimentary sequence is well-preserved in the Gamba area. Among these units, the Zongshan (71-65 Ma) and Zongpu (62-56 Ma) formations provide a unique opportunity for constraining the locus of the Tethyan Himalaya covering a critical stage of the IndiaAsia collision. Detailed lithological and biostratigraphic (Willems and Zhang, 1993; Wan et al., 2002a,b), sedimentological (Li et al., 2015), and geochemical (Wang et al., 2008; Q. Zhang et al., 2019) investigations provide a solid foundation for paleomagnetic studies.

Characteristic remanent magnetizations (ChRMs) reported from the Zongshan and Zongpu formations in the Gamba area passed positive fold and reversal tests, along with internally consistent magnetostratigraphy and biostratigraphic ages (71-56 Ma), permitting the original authors to interpret them as primary (Patzelt et al., 1996; Yi et al., 2011). However, based on the detailed rock magnetic and petrographic studies, along with a reanalysis of the fold test performed on the Zongpu Formation, Huang et al., $(2017 \mathrm{a}, \mathrm{b})$ argued for a widespread remagnetization via orogenic fluids in the Gamba area, and thus the paleomagnetic poles obtained from Zongpu Formation limestones can no longer be used to constrain the geometry of the India-Asia collision. As a response, Yi et al. (2017) addressed the reliability of their fold tests performed on the Zongpu and Zongshan formations and argued for an acquisition of the ChRMs in the early diagenetic stage.

On the basis of rock magnetism and SEM observations incorporating EDS analysis, Huang et al., (2017a,b, 2019) argued for the presence of abundant authigenic magnetites in carbonates preserved within the Tethyan domain of Tibet. These authigenic magnetites were suggested to result from a partial or complete replacement of pyrite crystals/framboids by secondary magnetites that were responsible for a widespread chemical remagnetization in the Gamba and Tring area, Tethyan Himalaya (Huang et al., 2017a,b). However, authigenic magnetic minerals are common for marine sediments due to the diagenesis during the burial process that may alter the combination of magnetic components (Roberts, 2015 and references therein) and complicate the discrimination of rock magnetic parameters. The authigenic magnetic spherules cannot be directly related to a chemical 
remagnetization (Saffer and McCabe, 1992; Suk et al., 1992), although the ability of carrying stable remanence of these magnetic spherules remains elusive (Xu et al., 1994; Suk and Halgedahl, 1996). Moreover, as EDS analyses cannot distinguish magnetic particles among magnetite, hematite, and goethite due to the imprecise measurement of Fe/O ratios (Sun and Jackson, 1994; Xu et al., 1998; Weil and Van der Voo, 2002; Franke et al., 2007), the arguments by Huang et al., (2017a,b, 2019) needs to be further studied.

In an effort to clarify the type and origin of the magnetic carriers in the Zongpu carbonates, we carry out a combined study integrating optical microscopy, SEM/TEM observations, and Raman spectroscopy measurements on thin sections and magnetic extracts of pilot samples from the Zongpu Formation in the Gamab area, Tethyan Himalaya. By this way, we further evaluated the nature of ChRMs reported from the Zongpu Formation by previous studies.

\section{Sampling sites and experimental methods}

Figure 1 illustrates the structure of the Indus-Yarlung Zangbo suture zone, in which paleomagnetic sampling localities and lithostratigraphic units are indicated. Detailed geological background is available in many previous studies (e.g., Wan et al., 2002a,b; Yi et al., 2011; Li et al., 2015; Huang et al., 2017a). The Paleocene carbonate rocks of the Zongpu Formation were deposited in a shallow-marine carbonate ramp on the northern Indian passive margin (Li et al., 2015). The Zongpu Formation is divided into four members by lithology; massive limestone (Member I), marls (Member II), nodular limestones (Member III), and well-bedded limestones (Member IV) (Willems and Zhang, 1993). Polished thin sections (xg38-3, xg160-1, xg145-3, and xg121-1) were processed on samples collected by Yi et al. (2011) (red dots in Figure 1C). In addition, block limestone samples (GB) of $\sim 1$ kilogram in weight was collected from the top of the Zongpu Formation for a magnetic extraction and SEM/TEM observations (Section A of Yi et al. (2011), Figure 1C).

Raman spectra measurements were conducted using a Raman spectrometer (LabRAM HR Evolution) equipped with a laser (excitation wavelength of 532nm) in the School of Earth and Space Sciences (SESS), Peking University. Laser power was reduced by a filter to about $1 \mathrm{~mW}$ to avoid the transformation of magnetite, goethite, and pyrite (Hanesch, 2009). Data were obtained with a spectral resolution of $1 \mathrm{~cm}^{-1}$ across the $100-1500 \mathrm{~cm}^{-1}$ wavenumber offset range. The experiment was carried out under an objective lens with 100 times magnification. Because of the low laser powers, more than ninety seconds integration time for individual measurements and 10 accumulations were set to improve the signal-to-noise ratio. In this study, Raman spectra were provided without smoothing or fitting to present the original results during the measurements.

To further examine the magnetic properties, the carbonate rock samples were first disaggregated and then put in buffered acetic acid to dissolve $(\mathrm{pH}=4)$ for several days. Magnetic extraction is performed using a self-designed magnetic probe extraction apparatus (Figure S1A). The slurry flowed through a tube with dispersed fine magnetic fractions and pumped continuously through the extraction equipment. Improved extraction-related procedures, following Hounslow et al. (1999), were used to avoid dissolution effects of ultrafine magnetic particles in samples (Sun and I 9 (4)

Magnetic extracts of pilot samples were prepared for SEM observation as thin sections using resin as an adhesive (Figure S1B). An alternative and highly recommended procedure to prepare SEM samples was to drop the solutions with magnetic extracts on a monocrystalline silicon wafer (Figure S1C). To prepare TEM specimens, distilled water with magnetic extracts was moved to a 
small container. A rare-earth magnet hovered $\sim 1 \mathrm{~cm}$ above the TEM grid which was floated on the surface of the solutions, to attract magnetic extracts for $\sim 5$ min (Figure S1D). EDS, electron backscatter diffraction (EBSD), and photographs were performed with SEM/ESEM system at SESS and Electron Microscopy Laboratory (EML) in the School of Physics, Peking University. The TEM was performed using a JEOL 2100 TEM $(200 \mathrm{kV})$ at the Institute of Geology and Geophysics, Chinese Academy of Sciences (IGGCAS).

\section{Results}

\subsection{Optical petrography and Raman spectroscopy analysis}

An analysis of the iron oxide-sulfide assemblages in the thin sections (xg38-3, xg160-1, xg1453 , and $\times g$ 121-1) and magnetic extracts (GB) under reflected white light shows that pyrite-substituted by iron oxides were the most abundant magnetic phase of the Zongpu Formation (Figures 2A-2D, 2I$2 \mathrm{~L}$, and S2). Based on the blood-red internal color under plane-polarized light (Figures 2E-2H, 2M$2 \mathrm{P}$ ), we interpret the iron oxides with poor crystallinity as fine-grained pigmentary hematite. Goethite phases, displaying intense brownish yellow-orange internal reflections, are identified around hematite pseudoframboids (Figures 2D, 2J-2L). The iron sulfides, inferred as pyrite due to the bright-brassy colored reflections with a speckly appearance, yielded two morphologic groups: (1) framboid spherules (Figures 2A, 2B, and 2I) and (2) large euhedral grains (Figures 2C and 2D). The abundant occurrence of the pigmentary hematite and goethite along calcite boundaries and/or intergranular dissolved voids are noticeable. In contrast, the extensive presence of pyrite (framboids and euhedral grains) is well-preserved in calcite crystals as inclusions. Magnetite was not identified by optical microscope observation probably due to its low concentration, although it was supposed to be the main magnetic carrier in the limestones of the Zongpu Formation (Yi et al., 2011; Huang et al., 2017a).

Furthermore, the Raman spectrum investigations indicate the presence of hematite, goethite, and pyrite (Figure 3). These results are consistent with our observations under the optical microscope. As compared with the corresponding spectra of minerals shown in Hanesch (2009) and the RRUFF database (https://rruff.info), the offset peaks might well be caused by different crystallinities of the natural minerals.

\subsection{SEM observations of magnetic extracts}

Abundant pure iron oxides were observed from magnetic extracts by SEM observation. These submicron iron oxide grains are presented in various morphology, consisting of broken-octahedral, subangular, irregular, and well-rounded crystals (Figures 4A-4J), suggestive of a detrital origin. The acquired Electron Back-scattering Patterns (EBSPs) for these grains show a spinel pattern (Figures $4 \mathrm{M}-4 \mathrm{P}$ ) that confirm a detrital origin for magnetites, although there may be hematite in some cases. Interestingly, we also found several euhedral magnetic crystals with clear particle boundaries, about $50-100 \mathrm{~nm}$ in size (Figures 4K and 4L). Accordingly, we suggest that these submicron and nanoscale magnetite particles fit the size range of SD and PSD (Dunlop and Özdemir, 1997) and are the possible remanence carrier in the limestones of the Zongpu Formation in the Gamba area.

Despite the frequent occurrence of detrital magnetite, iron oxide spherules were also found in the magnetic extracts (Figure 4A). EDS line scanning and mapping show that the iron oxide assemblage contains $\mathrm{S}$ in addition to $\mathrm{Fe}$ and $\mathrm{O}$ in a form of pseudoframboid (Figure 5). Given that cosmic spherules usually contain a low content of Ni (Brownlow et al., 1966) which was not detected by the EDS analysis, we exclude the possibility of cosmogenesis. Along with our observations in thin 
164 sections, we argue that these pseudoframboids are iron (hydr)oxides (hematite and/or goethite) that

165 substitute framboidal pyrite (Suk et al., 1990).

\section{$166 \quad 3.3 \quad$ TEM observations of magnetic extracts}

167 The TEM observations reveal that magnetic grains with variable grain sizes are commonly 168 present in magnetic extracts from the Zongpu Formation (Figures 6A-6D). Further high-resolution

169 TEM (HRTEM) and selected area electron diffraction (SAED) analyses were carried out to determine 170 the crystal structure of the magnetic particles. All analyzed magnetic minerals, including submicron and nanosized particles, have clear lattice fringes (Figures 6E and 6F) and sharp diffraction patterns (Figures 6G-6I) which indicate that the analyzed magnetic minerals are titanomagnetite and magnetite with well-developed crystallinity.

The TEM images revealed presence of both nanosized and euhedral magnetic crystals for the studied samples (Figures 6C, 6I, and 6L). The grain size of magnetite and titanomagnetite ranges from tens of $\mathrm{nm}$ to several $\mu \mathrm{m}$. Non-spheroidal iron oxides are observed in TEM. Together with the EDS spectra (Figures 6J-6L) and mineral morphologies, we believe that the remanence magnetic carrier should be detrital magnetite and/or euhedral magnetic particles from the Zongpu Formation in the Gamba area.

\section{$180 \quad 3.4 \quad$ Characteristics of demagnetization}

Previous rock magnetic investigations indicate the main magnetic carriers of remanence are magnetite from most Zongpu carbonates in the Gamba area, in addition, some of which detected goethite and hematite (Yi et al., 2011). All specimens were subjected to alternating field (AF) demagnetization up to $89 \mathrm{mT}$ in the light of their relatively weak natural remnant magnetization (NRM). Two remnant magnetization components were isolated in the majority of specimens (Figure 7A-F). After removal of a viscous component, xg0-3, xg38-3, and xg145-2 yield a stable characteristic remanence (ChRM) (Figure 7A, B, and D). Some specimens reveal an unstable demagnetization trajectory (xg121-2, and xg160-1; Figure 7C, E, and F) which were discarded for further discussion (Yi et al., 2011).

\section{Discussion}

\subsection{Origin of the euhedral magnetite in nanoscale}

SD euhedral magnetites were observed in the magnetic extracts (Figures 4K, 4L, and 6C). There are two possible origins for such magnetic particles in sediments: (1) the magnetic inclusion as erosional detritus from igneous and metamorphic rocks (e.g., Chang et al., 2016); (2) biogenic magnetite (Kopp and Kirschvink, 2008). Both types of magnetic particles are able to carry stable paleomagnetic signals over billions of years (Kirschvink and Lowenstam, 1979; Tarduno et al., 2006; Tarduno et al., 2010). Usually, most of the magnetic nanoparticle inclusions hosted within silicate crystals show high content of $\mathrm{Si}$ and low content of Ti that can be identified by EDS analyses (Chang et al., 2016). In this study, however, only very low content of Si and no Ti were detected from the euhedral magnetic crystals (Figure 6L). Furthermore, silicate minerals (e.g., plagioclase and clinopyroxene) were not observed in thin sections (Figures 2 and S4), probably due to the low clastic influx and high carbonate saturation during deposition of the Zongpu Formation (Li et al., 2015). In this case, the origin of euhedral magnetite in nanoscale from silicate-hosted magnetic mineral inclusions is highly unlikely. We suggest the nanosized and euhedral magnetic particles are biogenic magnetite that is capable of carrying stable remanences in limestones (Chang et al., 1987). Further 
study shouldbe required to detect robust evidence of biogenic magnetite based on a broader observation of magnetic extracts from Zongpu carbonates in the Gamba area.

208

209

210

211

212

213

214

215

216

217

218

219

220

\subsection{The possible origin of iron oxide spherules}

In addition to the detrital and biogenic magnetites observed in magnetic extracts, iron oxide spherules were also identified from the Zongpu Formation in the Gamba area (Figures 4, 5, and S2). Several previous studies attribute the remagnetization of carbonates to the replacement of framboidal pyrite by oxidation that is related to orogenic fluids (see review by McCabe and Elmore, 1989). However, the photomicrographs of limestone samples in Huang et al. (2017a) and section A of Yi et al. (2011) present well-preserved fossils (benthic foraminifer, echinoderm, ostracod, and green algae) with particles/matrix support and show no sign of orogenic-type fluids (Figure S4 and S5; Li and $\mathrm{Hu}, 2020)$. Besides, the variations of carbon and oxygen isotope of bulk carbonate cover the key interval of the Paleocene-Eocene thermal maximum (PETM) (Q. Zhang et al., 2019). The strontium isotopic ratios $\left({ }^{87} \mathrm{Sr} /{ }^{86} \mathrm{Sr}\right)$ of calcite are comparable with the global oceanic strontium isotope record (Wang et al., 2008) which indicates that the carbonates in the Gamba area have not been altered by orogenic fluids. The origin of iron oxide spherules should thus be explained in other mechanisms.

Suk et al. (1992) proposed different magnetic mineralogy for the primary and remagnetized carbonates. The iron sulfides (e.g., pyrite framboids) were moderately or completely oxidized to hematite in the former while a replacement of magnetite occurs in remagnetized carbonates. Moreover, oxidation of pyrite under modern atmosphere and groundwater conditions produces goethite and/or hematite (Todd et al., 2003; Sgavetti et al., 2009; Verron et al., 2019). Recently, a deep abiotic reaction mechanism of pyrite weathering in rocks was proposed which demonstrated that fracturing and erosion, in addition to atmospheric oxygen, control the reactivity of iron sulfide oxidation (Gu et al., 2020). Therefore, we suggest the large amounts of iron (hydr)oxides (e.g., goethite and hematite) observed in carbonates from the Zongpu Formation in the Gamba area were more likely oxidized from pyrite under aqueous solutions in contact with the atmosphere.

\subsection{Primary versus secondary origin of the ChRMs}

The secondary superparamagnetic (SP) to stable single domain (SSD) grain-sized magnetite is a general indicator for chemical remagnetization in carbonates which could well explain the remagnetization that occurred in the Paleozoic carbonates of North America (Channell and McCabe, 1994; Suk and Halgedahl, 1996; Xu et al., 1998; Elmore et al., 2006). A mix of SP and SD particles yields wasp-waisted hysteresis loops and distribution of Day plot along the SP-SD mixing line (Jackson and Swanson-Hysell, 2012). Nevertheless, magnetic minerals in different assemblage and shape anisotropy can also present contrasting coercivity distributions, resulting in wasp-waisted hysteresis loops (Jackson, 1990; Roberts et al., 1995; Newell and Merrill, 2000; Zwing et al., 2005; Jacson and Swanson-Hysell, 2012). It is generally difficult to interpret the magnetic grain size and mineralogy by wasp-waisted hysteresis loops or Day-plot only (Tauxe et al., 1996; Roberts et al., 2018). It also should be caution when using a Day diagram to diagnose remagnetization as occasionally 'false positives' and 'false negatives' results may present (Jackson and Swanson-Hysell, 2012; Roberts et al., 2018). Moreover, the validity of application of Day-plot in shallow-water carbonates, which are isolated from aqueous detrital input, remains unverified (Jackson and Swanson-Hysell, 2012). On the other hand, our SEM/TEM observations indicate the content of abundant detrital and biogenic magnetites in the investigated carbonates (Figures 4 and 6). The optical petrography and Raman spectra analyses present robust evidence that iron (hydr)oxides, i.e., goethite and hematite (Figures 2, 3, and S2), rather than magnetite, as substitutes of pyrite framboids. The imaginable detrital and biogenic magnetite, along with goethite and hematite, would yield wasp- 
waisted hysteresis loops and distribution of Day plot along the SP-SD mixing line which leads to an incorrect interpretation of remagnetization from Day plot locations (Huang et al., 2017a,b, 2019).

The argument of previous paleomagnetic investigation for a chemical remagnetization of the carbonate rocks in the Gamba area was mainly based on SEM and EDS interpretation (Huang et al., 2017a). Whereafter, the same authors performed analogous analytical processes on the Upper Cretaceous to Paleocene carbonates from the Tingri area in the Tethyan Himalaya and the Upper Triassic limestones in the eastern Qiangtang block, argued for a widespread remagnetization in the Tibetan Tethyan domain (Huang et al., 2017b, 2019). However, the critical "authigenic magnetite", along with the "orogenic fluids" are only speculated by the authors, regardless that conventional EDS techniques only have a semi-quantitative character which cannot directly distinguish the exact iron oxides. On the contrary, the geochemical evidence from the Zongpu Formation precludes the existence of widespread orogenic fluids as discussed above. Consequently, the remagnetization mechanism of chemical alteration suggested by Huang et al. (2017a) is problematic.

The presence of abundant detrital and biogenic magnetites in the Zongpu limestones precludes widespread chemical remagnetization in the Gamba area. The rock magnetic investigations (Yi et al., 2011; Huang et al., 2017a) and the characteristics of demagnetization (Figure 7) are consistent with high-resolution petrographic observations (Figures 2, 4, and 6). On the other hand, the occurrence of anatas in the underlying Jidula Formation suggests that the overlying Zongpu limestones were never heated over $260^{\circ} \mathrm{C}$ (Patzelt et al., 1996) and hence exclude a thermal remagnetization in the Gamba area. Moreover, the ChRMs from Gamba carbonates yielded positive fold and reversal tests (Patzelt et al., 1996; Yi et al., 2011, 2017), and the paleomagnetic pole from the Zongpu Formation hence meets all the criteria for a paleomagnetic study $(\mathrm{R}=7$ ) (Meert et al., 2020). We therefore concluded that detrital and biogenic magnetites are the main magnetic carriers of primary remanence and the paleomagnetic results reported by Yi et al. (2011) from the Gamba area can still be used for paleogeographic reconstruction.

\section{Conclusion and perspective}

The high-resolution petrographic study was carried out on Paleocene carbonates (the Zongpu Formation) from Gamba, South Tibet. Electron microscopic observation of magnetic extracts identified abundant detrital and biogenic magnetites. Minor framboidal iron oxides were also identified using SEM, optical microscope, and Raman spectrum investigations. However, the magnetic minerals in these framboids are pigmentary hematite and/or goethite rather than authigenic magnetite. Therefore, the ChRMs of the limestones from the Zongpu Formation in the Gamba area are carried by detrital and biogenic magnetites. The arguments of chemical remagnetization, based on oversimplified semiquantitative EDS analyses and incomplete rock magnetic measurements in previous studies, should be rejected. Instead, the paleomagnetic data obtained from the Paleocene carbonates in the Gamba area can be used for tectonic reconstructions. We suggest that comprehensive analyses of magnetic extracts with advanced EBSD and TEM are extremely important and favorable to diagnose the substantial magnetization carriers in carbonate rocks. The remagnetization hypotheses in Paleocene carbonates from the Tingri area, Tethyan Himalaya, and the Late Triassic carbonates from the Qiangtang terrane require further study based on the thorough petrographic and mineralogical investigations to determine the origin of the magnetization.

\section{$6 \quad$ Funding}


This study was supported by grants from the National Natural Science Foundation of China (Grants No. 92055205, 41888101) and the Second Tibetan Plateau Scientific Expedition and Research Program (STEP; Grant No. 2019QZKK0703).

\section{Acknowledgments}

297 We are grateful to Xu Tang at the Electron Microscopy Laboratory, IGGCAS for helping with TEM operation and David Richard and Richard T. Wilkin for helpful discussions.

\section{References}

300

301

302

303

304

305

306

307

308

309

310

311

312

313

314

315

316

317

318

319

320

321

322

323

324

325

326

327

Aitchison, J.C., Ali, J.R., and Davis, A.M. (2007). When and where did India and Asia collide? Journal of Geophysical Research 112(B5). doi: 10.1029/2006jb004706.

Ali, J.R., and Aitchison, J.C. (2008). Gondwana to Asia: Plate tectonics, paleogeography and the biological connectivity of the Indian sub-continent from the Middle Jurassic through latest Eocene (166-35Ma). Earth-Science Reviews 88, 145-166. doi: 10.1016/j.earscirev.2008.01.007.

An, W., Hu, X., Garzanti, E., Wang, J.G., and Liu, Q. (2021). New Precise Dating of the India - Asia Collision in the Tibetan Himalaya at 61 Ma. Geophysical Research Letters 48(3). doi: $10.1029 / 2020 \mathrm{gl} 1090641$.

Besse, J., Courtillot, V., Pozzi, J., Westphal, M., and Zhou, Y. (1984). Palaeomagnetic estimates of crustal shortening in the Himalayan thrusts and Zangbo suture. Nature 311(5987), 621-626. doi: $10.1038 / 311621 \mathrm{a} 0$.

Brownlow, A.E., Hunter, W., and Parkin, D.W. (1966). Cosmic Spherules in a Pacific Core. Geophysical Journal International 12(1), 1-13. doi: 10.1111/j.1365-246X.1966.tb03096.x.

Chang, L., Roberts, A.P., Heslop, D., Hayashida, A., Li, J., Zhao, X., et al. (2016). Widespread occurrence of silicate - hosted magnetic mineral inclusions in marine sediments and their contribution to paleomagnetic recording. Journal of Geophysical Research: Solid Earth 121, 8415-8431. doi: 10.1002/2016JB013109.

Chang, S., Kirschvink, J.L., and Stolz, J.F. (1987). Biogenic magnetite as a primary remanence carrier in limestone deposits. Physics of the Earth and Planetary Interiors 46(1-3), 289-303. doi: 10.1016/0031-9201(87)90191-9.

Channell, J.E.T., and McCabe, C. (1994). Comparison of magnetic hysteresis parameters of unremagnetized and remagnetized limestones. Journal of Geophysical Research: Solid Earth 99(B3), 4613-4623. doi: 10.1029/93JB02578.

Ding, L., Kapp, P., and Wan, X. (2005). Paleocene - Eocene record of ophiolite obduction and initial India - Asia collision, south central Tibet. Tectonics 24(3). doi: 10.1029/2004TC001729.

Dunlop, D.J., and Özdemir, Ö. (1997). Rock magnetism: fundamentals and frontiers. Cambridge university press.

This is a provisional file, not the final typeset article 
328

329

330

331

332

333

334

335

336

337

338

339

340

341

342

343

344

345

346

347

348

349

350

351

352

353

354

355

356

357

358

359

360

361

362

363

364

365

Dupont-Nivet, G., Lippert, P.C., Van Hinsbergen, D.J.J., Meijers, M.J.M., and Kapp, P. (2010). Palaeolatitude and age of the Indo-Asia collision: palaeomagnetic constraints. Geophysical Journal International 182(3), 1189-1198. doi: 10.1111/j.1365-246X.2010.04697.x.

Elmore, R.D., Lee-Egger Foucher, J., Evans, M., Lewchuk, M., and Cox, E. (2006). Remagnetization of the Tonoloway Formation and the Helderberg Group in the Central Appalachians: testing the origin of syntilting magnetizations. Geophysical Journal International 166(3), 1062-1076. doi: 10.1111/j.1365-246X.2006.02875.x.

Franke, C., Pennock, G., Drury, M.R., Engelmann, R., Lattard, D., Garming, J.F.L., et al. (2007). Identification of magnetic Fe-Ti oxides in marine sediments by electron backscatter diffraction in scanning electron microscopy. Geophysical Journal International 170(2), 545555. doi: 10.1111/j.1365-246X.2007.03410.x.

Gu, X., Heaney, P.J., Reis, F.D.A., and Brantley, S.L. (2020). Deep abiotic weathering of pyrite. Science 370(6515). doi: 10.1126/science.abb8092.

Hanesch, M. (2009). Raman spectroscopy of iron oxides and (oxy) hydroxides at low laser power and possible applications in environmental magnetic studies. Geophysical Journal International 177(3), 941-948. doi: 10.1111/j.1365-246X.2009.04122.x.

Hounslow, M.W., Maher, B.A., Walden, J., Oldfield, F., and Smith, J. (1999). Laboratory procedures for quantitative extraction and analysis of magnetic minerals from sediments. Environmental Magnetism, A Practical Guide. Quaternary Research Association, Technical Guide 6, 139164.

Hu, X., Garzanti, E., Wang, J., Huang, W., An, W., and Webb, A. (2016). The timing of India-Asia collision onset-Facts, theories, controversies. Earth-Science Reviews 160, 264-299. doi: 10.1016/j.earscirev.2016.07.014.

Huang, W., Jackson, M.J., Dekkers, M.J., Zhang, Y., Zhang, B., Guo, Z., et al. (2019). Challenges in isolating primary remanent magnetization from Tethyan carbonate rocks on the Tibetan Plateau: Insight from remagnetized Upper Triassic limestones in the eastern Qiangtang block. Earth and Planetary Science Letters 523, 115695. doi: 10.1016/j.eps1.2019.06.035.

Huang, W., Lippert, P.C., Jackson, M.J., Dekkers, M.J., Zhang, Y., Li, J., et al. (2017a). Remagnetization of the Paleogene Tibetan Himalayan carbonate rocks in the Gamba area: Implications for reconstructing the lower plate in the India-Asia collision. Journal of Geophysical Research-Solid Earth 122(2), 808-825. doi: 10.1002/2016jb013662.

Huang, W., Lippert, P.C., Zhang, Y., Jackson, M.J., Dekkers, M.J., Li, J., et al. (2017b). Remagnetization of carbonate rocks in southern Tibet: Perspectives from rock magnetic and petrographic investigations. Journal of Geophysical Research: Solid Earth 122(4), 24342456. doi: 10.1002/2017jb013987.

Jackson, M. (1990). Diagenetic sources of stable remanence in remagnetized Paleozoic cratonic carbonates: A rock magnetic study. Journal of Geophysical Research: Solid Earth 95(B3), 2753-2761. doi: 10.1029/JB095iB03p02753. 
Jackson, M., and Swanson-Hysell, N.L. (2012). Rock magnetism of remagnetized carbonate rocks: Another look. Geological Society, London, Special Publications 371(1), 229-251. doi: 10.1144/SP371.3.

Jagoutz, O., Macdonald, F.A., and Royden, L. (2016). Low-latitude arc-continent collision as a driver for global cooling. Proceedings of the National Academy of Sciences 113(18), 49354940. doi: 10.1073/pnas.1523667113.

Kirschvink, J.L., and Lowenstam, H.A. (1979). Mineralization and magnetization of chiton teeth: paleomagnetic, sedimentologic, and biologic implications of organic magnetite. Earth and Planetary Science Letters 44(2), 193-204. doi: 10.1016/0012-821X(79)90168-7.

Kopp, R.E., and Kirschvink, J.L. (2008). The identification and biogeochemical interpretation of fossil magnetotactic bacteria. Earth-Science Reviews 86(1), 42-61. doi: 10.1016/j.earscirev.2007.08.001.

Leech, M.L., Singh, S., Jain, A., Klemperer, S.L., and Manickavasagam, R. (2005). The onset of India-Asia continental collision: early, steep subduction required by the timing of UHP metamorphism in the western Himalaya. Earth and Planetary Science Letters 234(1-2), 8397. doi: 10.1016/j.epsl.2005.02.038.

Li, J., and Hu, X. (2020). A photomicrograph dataset of Late Cretaceous to Early Paleogene carbonate rocks in Tibetan Himalaya. China Scientific Data 5. doi: 10.11922/csdata.2020.0072.zh.

Li, J., Hu, X., Garzanti, E., An, W., and Wang, J. (2015). Paleogene carbonate microfacies and sandstone provenance (Gamba area, South Tibet): Stratigraphic response to initial India-Asia continental collision. Journal of Asian Earth Sciences 104, 39-54. doi: 10.1016/j.jseaes.2014.10.027.

Ma, Y., Yang, T., Bian, W., Jin, J., Zhang, S., Wu, H., et al. (2016). Early Cretaceous paleomagnetic and geochronologic results from the Tethyan Himalaya: Insights into the Neotethyan paleogeography and the India-Asia collision. Sci Rep 6, 21605. doi: 10.1038/srep21605.

McCabe, C., and Elmore, R.D.J.R.o.G. (1989). The occurrence and origin of late Paleozoic remagnetization in the sedimentary rocks of North America. 27(4), 471-494.

Meert, J.G., Pivarunas, A.F., Evans, D., Pisarevsky, S.A., and Salminen, J.M. (2020). The magnificent seven: A proposal for modest revision of the quality index. Tectonophysics 790(5), 228549. doi: 10.1016/j.tecto.2020.228549.

Meng, J., Gilder, S.A., Wang, C., Coe, R.S., Tan, X., Zhao, X., et al. (2019). Defining the Limits of Greater India. Geophysical Research Letters. doi: 10.1029/2019g1082119.

Meng, J., Lhuillier, F., Wang, C., Liu, H., Eid, B., and Li, Y. (2020). Paleomagnetism of Paleocene Maastrichtian (60 - $70 \mathrm{Ma}$ ) Lava Flows From Tian Shan (Central Asia): Directional Analysis and Paleointensities. Journal of Geophysical Research: Solid Earth 125(9), e2019JB018631. doi: 10.1029/2019JB018631.

This is a provisional file, not the final typeset article 
403

404

405

406

407

408

409

410

411

412

413

414

415

416

417

418

419

420

421

422

423

424

425

426

427

428

429

430

431

432

433

434

435

436

437

438

439

Najman, Y., Appel, E., Boudagher-Fadel, M., Bown, P., Carter, A., Garzanti, E., et al. (2010). Timing of India-Asia collision: Geological, biostratigraphic, and palaeomagnetic constraints. Journal of Geophysical Research 115(B12). doi: 10.1029/2010jb007673.

Newell, A.J., and Merrill, R.T. (2000). Size dependence of hysteresis properties of small pseudo single - domain grains. Journal of Geophysical Research: Solid Earth 105(B8), 1939319403. doi: 10.1029/2000JB900122.

Patriat, P., and Achache, J. (1984). India-Eurasia collision chronology has implications for crust shortening and diving mechanism of plates. Nature 311(18), 615-621. doi: 10.1038/311615a0

Patzelt, A., Li, H., Wang, J., and Appel, E. (1996). Palaeomagnetism of Cretaceous to Tertiary sediments from southern Tibet: evidence for the extent of the northern margin of India prior to the collision with Eurasia. Tectonophysics 259(4), 259-284. doi: 10.1016/00401951(95)00181-6.

Roberts, A.P., Cui, Y., and Verosub, K.L. (1995). Wasp - waisted hysteresis loops: Mineral magnetic characteristics and discrimination of components in mixed magnetic systems. Journal of Geophysical Research: Solid Earth 100(B9), 17909-17924. doi: 10.1029/95JB00672.

Roberts, A.P., Tauxe, L., Heslop, D., Zhao, X., and Jiang, Z. (2018). A Critical Appraisal of the "Day" Diagram. Journal of Geophysical Research: Solid Earth 123(4), 2618-2644. doi: 10.1002/2017JB015247.

Saffer, B., and McCabe, C. (1992). Further studies of carbonate remagnetization in the northern Appalachian basin. Journal of Geophysical Research: Solid Earth 97(B4), 4331-4348. doi: 10.1029/91JB02746.

Sgavetti, M., Pompilio, L., Roveri, M., Manzi, V., Valentino, G., Lugli, S., et al. (2009). Two geologic systems providing terrestrial analogues for the exploration of sulfate deposits on Mars: Initial spectral characterization. Planetary and Space Science 57(5-6), 614-627. doi: 10.1016/j.pss.2008.05.010.

Suk, D., and Halgedahl, S.L. (1996). Hysteresis properties of magnetic spherules and whole rock specimens from some Paleozoic platform carbonate rocks. Journal of Geophysical Research: Solid Earth 101(B11), 25053-25075. doi: 10.1029/96JB02271.

Suk, D., Peacor, D., and Van der Voo, R. (1990). Replacement of pyrite framboids by magnetite in limestone and implications for palaeomagnetism. Nature 345(6276), 611-613. doi: $10.1038 / 345611 \mathrm{a} 0$.

Suk, D., Van der Voo, R., and Peacor, D.R. (1992). SEM/STEM observation of magnetic minerals in presumably unremagnetized Paleozoic carbonates from Indiana and Alabama. Tectonophysics 215(3-4), 255-272. doi: 10.1016/0040-1951(92)90356-B.

Sun, W., and Jackson, M. (1994). Scanning electron microscopy and rock magnetic studies of magnetic carriers in remagnetized early Paleozoic carbonates from Missouri. Journal of Geophysical Research: Solid Earth 99(B2), 2935-2942. doi: 10.1029/93JB02761. 
Tarduno, J.A., Cottrell, R.D., and Smirnov, A.V. (2006). The paleomagnetism of single silicate crystals: Recording geomagnetic field strength during mixed polarity intervals, superchrons, and inner core growth. Reviews of Geophysics 44(1), RG1002. doi: 10.1029/2005RG000189.

Tarduno, J.A., Cottrell, R.D., Watkeys, M.K., Hofmann, A., Doubrovine, P.V., Mamajek, E.E., et al. (2010). Geodynamo, Solar Wind, and Magnetopause 3.4 to 3.45 Billion Years Ago. Science 327(5970), 1238-1240. doi: 10.1126/science.1183445.

Tauxe, L., Mullender, T., and Pick, T. (1996). Potbellies, wasp - waists, and superparamagnetism in magnetic hysteresis. Journal of Geophysical Research: Solid Earth 101(B1), 571-583.

Todd, E.C., Sherman, D.M., and Purton, J.A. (2003). Surface oxidation of pyrite under ambient atmospheric and aqueous ( $\mathrm{pH}=2$ to 10$)$ conditions: electronic structure and mineralogy from X-ray absorption spectroscopy. Geochimica et Cosmochimica Acta 67(5), 881-893. doi: 10.1016/S0016-7037(02)00957-2.

Tong, Y., Yang, Z., Zheng, L., Yang, T., Shi, L., Sun, Z., et al. (2008). Early Paleocene paleomagnetic results from southern Tibet, and tectonic implications. International Geology Review 50(6), 546-562. doi: 10.2747/0020-6814.50.6.546

van Hinsbergen, D.J.J., Lippert, P.C., Dupont-Nivet, G., McQuarrie, N., Doubrovine, P.V., Spakman, W., et al. (2012). Greater India Basin hypothesis and a two-stage Cenozoic collision between India and Asia. Proceedings of the National Academy of Sciences 109(20), 7659-7664. doi: 10.1073/pnas.1117262109.

van Hinsbergen, D.J.J., Steinberger, B., Doubrovine, P.V., and Gassmöller, R. (2011). Acceleration and deceleration of India-Asia convergence since the Cretaceous: Roles of mantle plumes and continental collision. Journal of Geophysical Research 116(B6). doi: 10.1029/2010jb008051.

Verron, H., Sterpenich, J., Bonnet, J., Bourdelle, F., Mosser-Ruck, R., Lorgeoux, C., et al. (2019). Experimental study of pyrite oxidation at $100^{\circ} \mathrm{C}$ : implications for deep geological radwaste repository in claystone. Minerals $9(7), 427$. doi: 10.3390/min9070427.

Wan, X., Jansa, L.F., and Sarti, M. (2002a). Cretaceous and Paleogene boundary strata in southern Tibet and their implication for the India - Eurasia collision. Lethaia 35(2), 131-146. doi: 10.1080/002411602320183999.

Wan, X., Liang, D., and Li, G. (2002b). Palaeocene strata in Gamba, Tibet and influence of tectonism. Acta Geologica Sinica 76(2), 155-162. doi: 10.3321/j.issn:0001-5717.2002.02.002

Wang, X., Wan, X., and Li, G. (2008). Late Cretaceous to early Paleogene strontium isotopic stratigraphy in the Gamba area, Tibet. Geology in China 4, 598-607. doi: 10.3969/j.issn.10003657.2008.04.004

Weil, A.B., and Van der Voo, R. (2002). Insights into the mechanism for orogen - related carbonate remagnetization from growth of authigenic Fe - oxide: A scanning electron microscopy and rock magnetic study of Devonian carbonates from northern Spain. Journal of Geophysical Research: Solid Earth 107(B4), EPM 1-1-EPM 1-14. doi: 10.1029/2001JB000200.

This is a provisional file, not the final typeset article 
Willems, H., and Zhang, B. (1993). Cretaceous and lower Tertiary sediments of the Tibetan Tethys Himalaya in the area of Tingri (South Tibet, PR China). Geoscientific Investigation in the Tethyan Himalayas. Berichte aus dem Fachbereich Geowissenschaften der Universität Bremen 38, 28-47.

Xu, W., Van der Voo, R., and Peacor, D.R. (1994). Are magnetite spherules capable of carrying stable magnetizations? Geophysical Research letters 21(7), 517-520. doi: 10.1029/94GL00366.

Xu, W., Van der Voo, R., and Peacor, D.R. (1998). Electron microscopic and rock magnetic study of remagnetized Leadville carbonates, central Colorado. Tectonophysics 296(3-4), 333-362. doi: 10.1016/S0040-1951(98)00146-2.

Yang, T., Jin, J., Bian, W., Ma, Y., Gao, F., Peng, W., et al. (2019). Precollisional Latitude of the Northern Tethyan Himalaya From the Paleocene Redbeds and Its Implication for Greater India and the India-Asia collision. Journal of Geophysical Research: Solid Earth 124(11), 10777-10798. doi: 10.1029/2019JB017927.

Yang, T., Ma, Y., Bian, W., Jin, J., Zhang, S., Wu, H., et al. (2015). Paleomagnetic results from the Early Cretaceous Lakang Formation lavas: Constraints on the paleolatitude of the Tethyan Himalaya and the India-Asia collision. Earth and Planetary Science Letters 428, 120-133. doi: 10.1016/j.epsl.2015.07.040.

Yi, Z., Appel, E., and Huang, B. (2017). Comment on "Remagnetization of the Paleogene Tibetan Himalayan carbonate rocks in the Gamba area: Implications for reconstructing the lower plate in the India-Asia collision" by Huang et al. Journal of Geophysical Research-Solid Earth 122(7), 4852-4858. doi: 10.1002/2017jb014353.

Yi, Z., Huang, B., Chen, J., Chen, L., and Wang, H. (2011). Paleomagnetism of early Paleogene marine sediments in southern Tibet, China: Implications to onset of the India-Asia collision and size of Greater India. Earth and Planetary Science Letters 309(1-2), 153-165. doi: 10.1016/j.eps1.2011.07.001.

Yi, Z., Wang, T., Meert, J.G., Zhao, Q., and Liu, Y. (2021). An Initial Collision of India and Asia in the Equatorial Humid Belt. Geophysical Research Letters 48(9), e2021GL093408. doi: 10.1029/2021GL093408.

Yin, A., and Harrison, T.M. (2000). Geologic evolution of the Himalayan-Tibetan orogen. Annual Review of Earth and Planetary Sciences 28(1), 211-280. doi: 10.1146/annurev.earth.28.1.211.

Yuan, J., Yang, Z., Deng, C., Krijgsman, W., Hu, X., Li, S., et al. (2020). Rapid drift of the Tethyan Himalaya terrane before two-stage India-Asia collision. National Science Review. doi: 10.1093/nsr/nwaa173.

Zhang, Q., Willems, H., Ding, L., and Xu, X. (2019a). Response of larger benthic foraminifera to the Paleocene-Eocene thermal maximum and the position of the Paleocene/Eocene boundary in the Tethyan shallow benthic zones: Evidence from south Tibet. Geological Society of America Bulletin 131(1-2), 84-98. doi: 10.1130/B31813.1. 
515

516

517

518

519

520

521

522

523

524

525

526

527

528

529

530

531

532

533

534

535

536

537

538

539

540

541

542

543

544

545

546

547

548

549

550

551

552

553

554

Zhang, Y., Huang, B.C., and Zhao, Q. (2019b). New paleomagnetic positive proof of the rigid or quasi-rigid Greater Indian Plate during the Early Cretaceous. Chinese Science Bulletin 64(21), 2225-2244. doi: 10.1360/n972019-00196.

Zwing, A., Matzka, J., Bachtadse, V., and Soffel, H. (2005). Rock magnetic properties of remagnetized Palaeozoic clastic and carbonate rocks from the NE Rhenish massif, Germany. Geophysical Journal International 160(2), 477-486. doi: 10.1111/j.1365-246X.2004.02493.x.

\section{Figure captions}

Figure 1. (A) Schematic structural map of the India-Asia collision zone. (B) Geologic map of the Gamba area with the sampling locations of Yi et al. (2011) (red star) and Huang et al., (2017a) (green star). (C)

Lithostratigraphy of section A of Yi et al. (2011). Red and blue dots indicate the sampling levels for samples collected for thin sections observation and magnetic extraction, respectively.

Figure 2. Photomicrographs illustrating the iron oxide mineralogical features of limestones from the Zongpu Formation in the Gamba area under reflected light (A-D, I-L) and plane-polarized light (E-H, M-P) images. White dots in Figures. 2C and 2L represent the spots of Raman spectroscopy analyses in Figure 3. $\mathrm{Cal}=$ calcite; $\mathrm{Gt}=$ goethite $; \mathrm{pHem}=$ pigmentary hematite Py $=$ pyrite .

Figure 3. Raman spectrum of the limestones from the Zongpu Formation. Three types of Fe-O-S minerals, i.e., hematite $\left(222 \mathrm{~cm}^{-1}, 297 \mathrm{~cm}^{-1}\right.$, and $\left.390 \mathrm{~cm}^{-1}\right)(\mathrm{A})$, goethite $\left(208 \mathrm{~cm}^{-1}, 270 \mathrm{~cm}^{-1}\right.$ and $\left.380 \mathrm{~cm}^{-1}\right)(B)$ and pyrite $\left(344 \mathrm{~cm}^{-1}\right.$ and $\left.379 \mathrm{~cm}^{-1}\right)$ (C) can be identified in the Raman spectra.

Figure 4. (A-L) Secondary-electron SEM images of magnetic extracts in limestones of the Zongpu Formation. ( $\mathrm{M}$ and $\mathrm{P}$ ) EBSPs solution of iron oxides corresponding to the white circles indicated in Figure 4 A-C. Zone axes are labeled using Miller indices. Note the white circle areas are not as accurate as that was shown in the images, because of the low resolution of SEM during EBSD analyses. White arrows in Figures $4 \mathrm{~K}$ and $4 \mathrm{~L}$ indicate the possible occurrence of biogenic magnetite. White dots represent the EDS spots as shown in Figure S3. $[\mathrm{Fe}-\mathrm{O}]=$ iron oxides; $\mathrm{Mag}=$ magnetite.

Figure 5. Elemental mapping exhibits elemental compositions and distributions of an iron-oxidized framboid. (A) SEM image of a framboid with line scan by energy spectrum. (B-D) Fe, S, and O elements are scattered in most areas. White arrows show significant variation in the distributions of $\mathrm{Fe}, \mathrm{O}$, and $\mathrm{S}$ elements.

Figure 6. High-resolution TEM and SAED analyses of magnetic minerals for magnetic extracts from limestones in the Zongpu Formation. (A-D) Bright-field TEM images at progressively higher magnifications reveal characteristics of mixed magnetic particles with different sizes. (E-F) Clear lattice fringes for the magnetic minerals are observed. The lattice fringes in (F) correspond to <311> plane of titanomagnetite. (G-I) Ring-like and spot-like SAED patterns indicate the particle aggreget and single particle, respectively. The corresponding Miller indices (hkl) are illustrated. (J-L) EDS spectra of the magnetic particles in B-D. The particles in different sizes are magnetite $(B, C)$ and titanomagnetite (D).

Figure 7. Orthogonal (Zijderveld) vector plots of specimens from Yi et al. (2011) corresponding to the samples of magnetic extraction and thin sections. Drections are plotted in-situ; solid and open circles represent vector endpoints projected onto horizontal and vertical planes, respectively.

This is a provisional file, not the final typeset article 
Running Title 

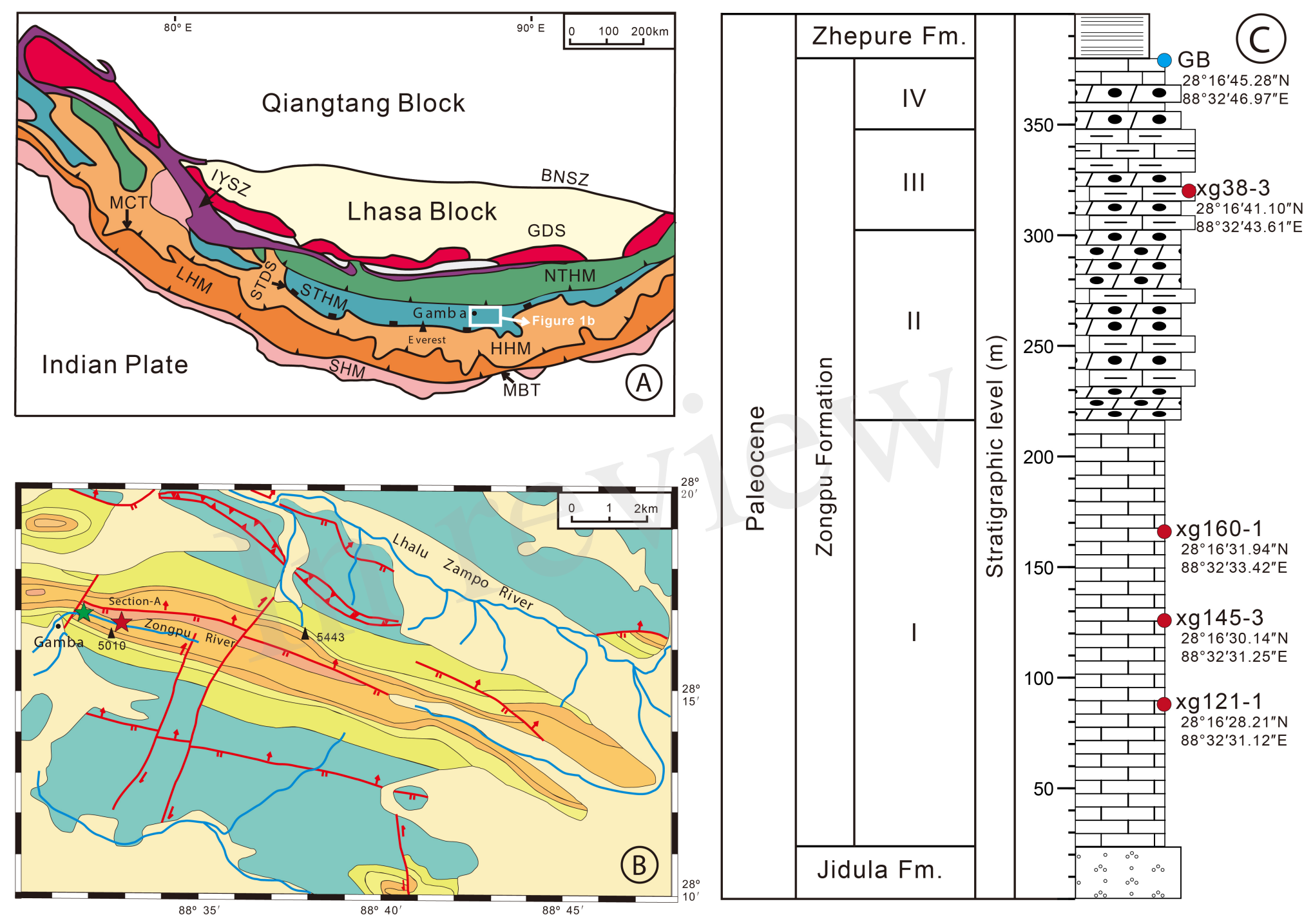

Jidula Fm.

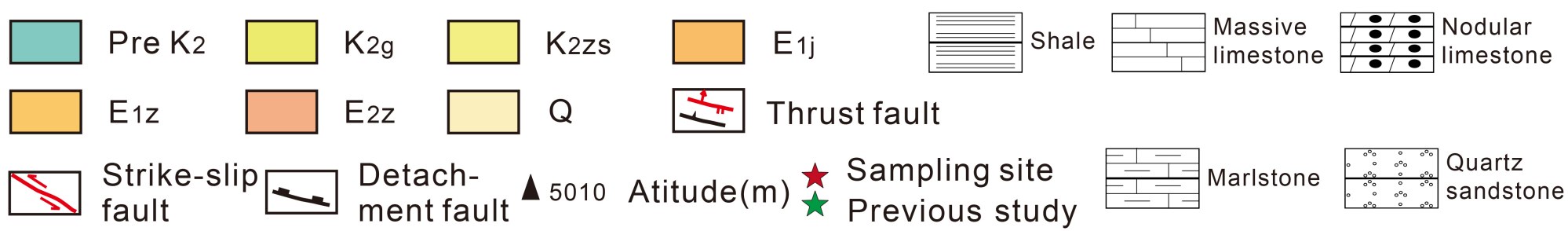


Figure 2.JPEG

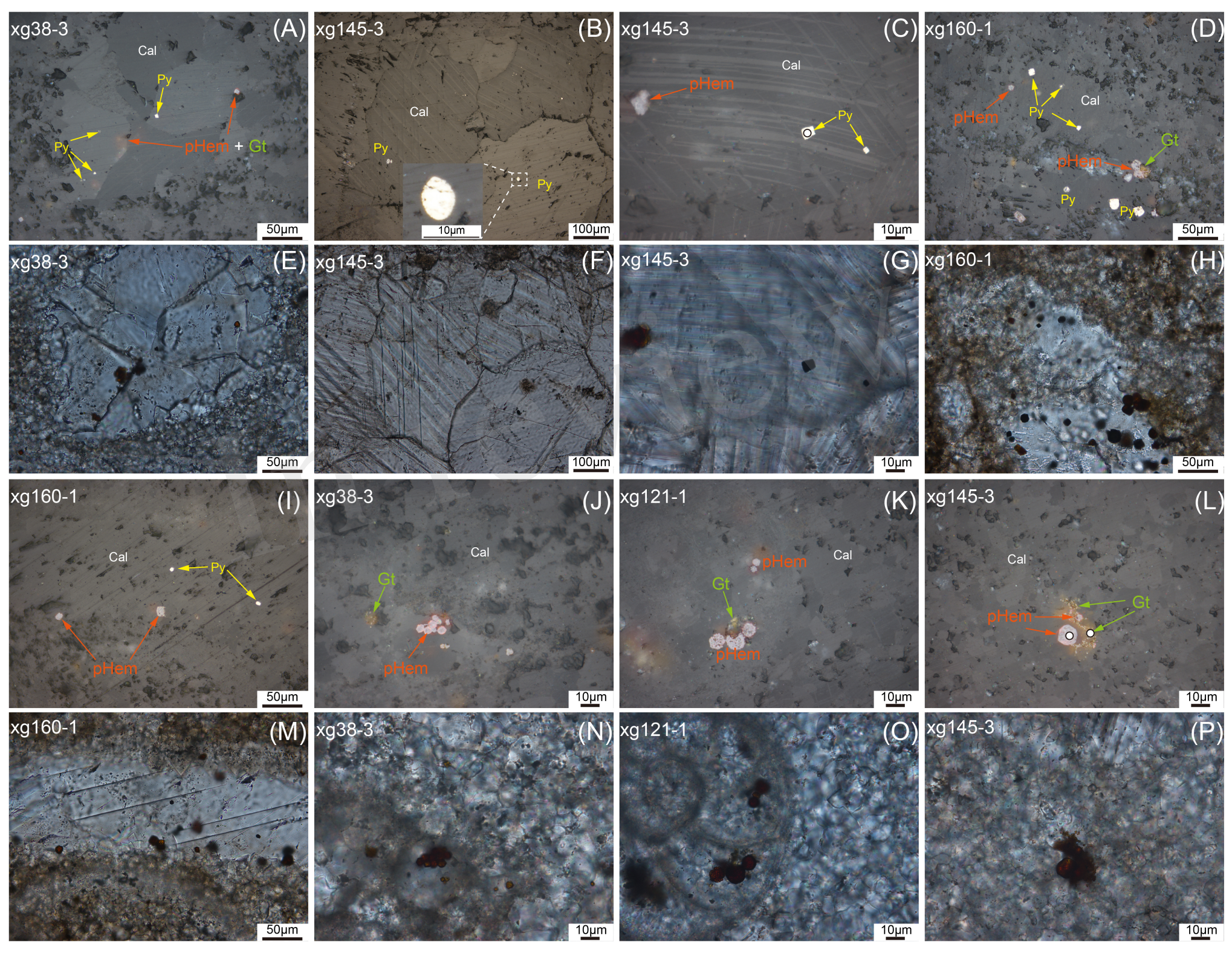


Figure 3.JPEG
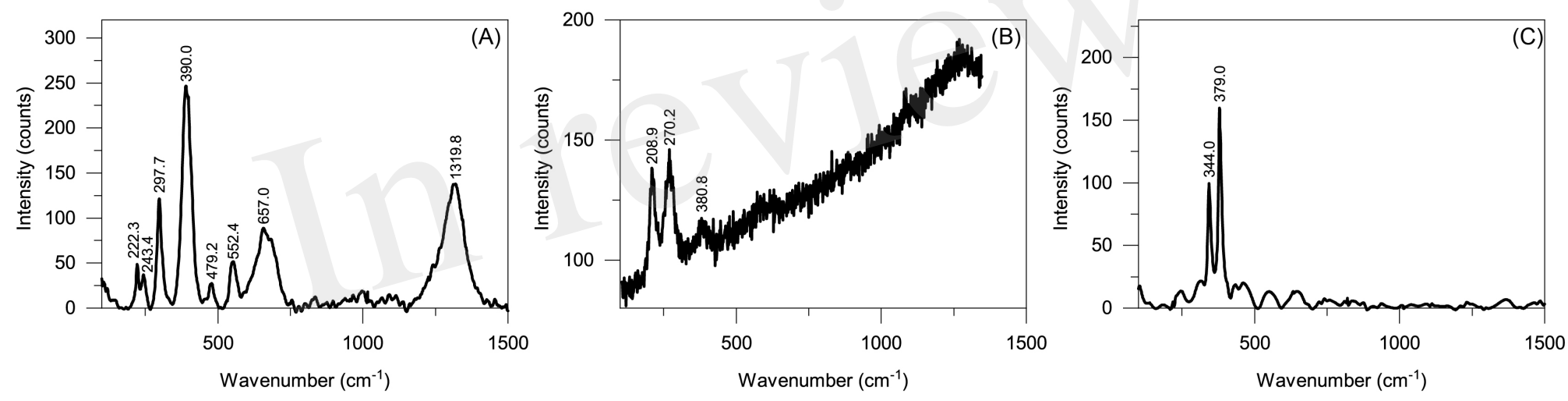
Figure 4.JPEG
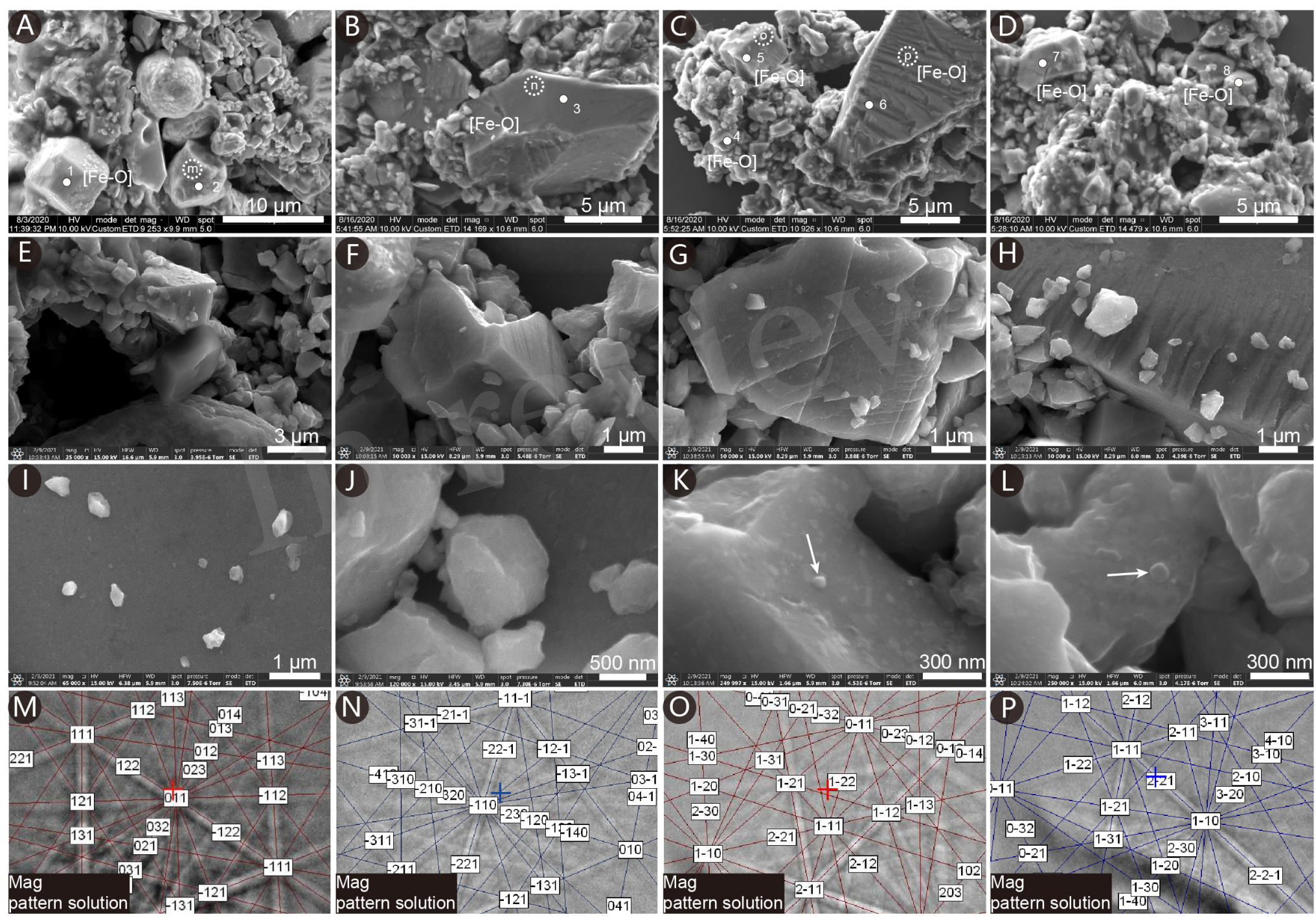

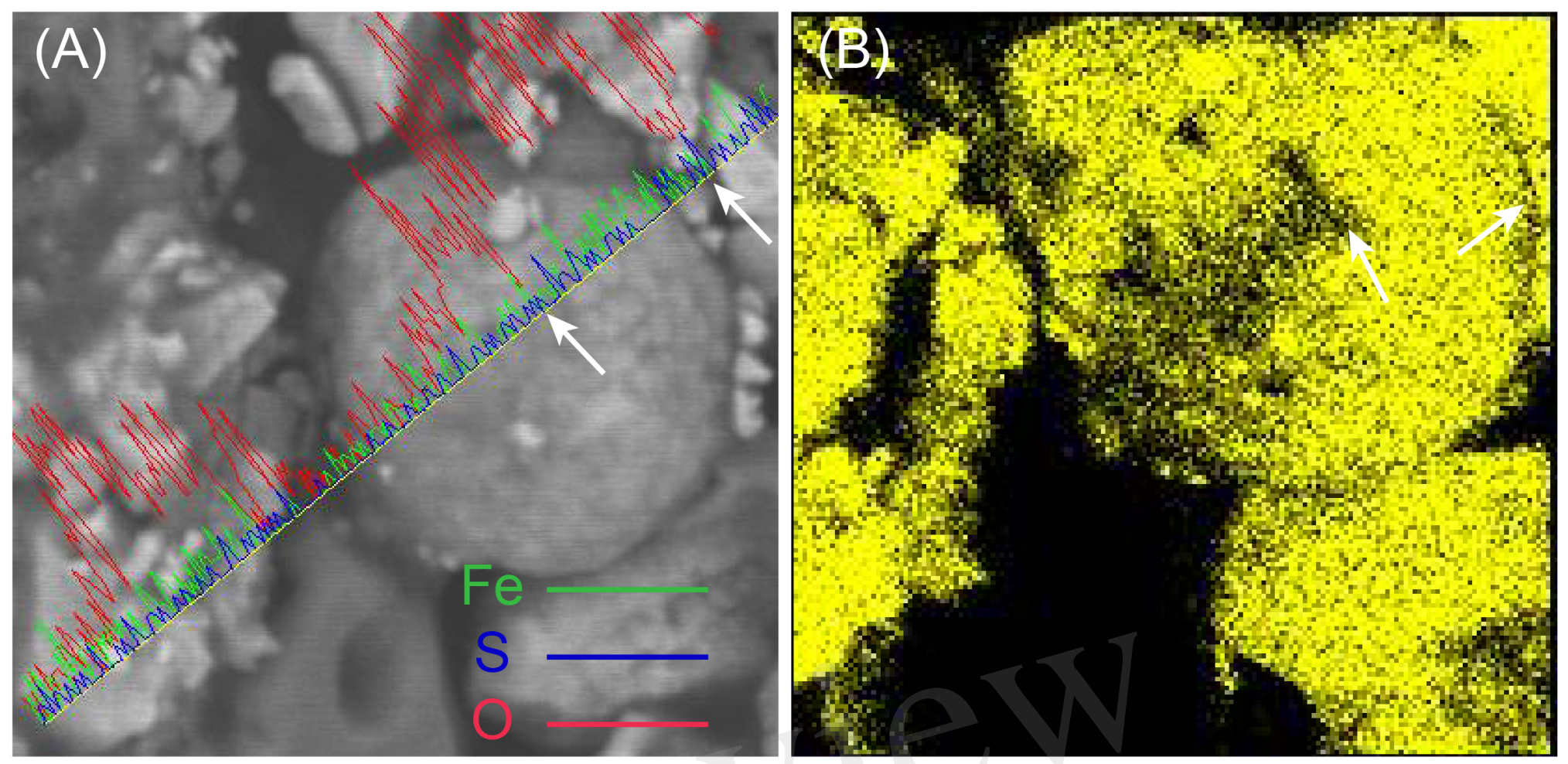

\section{$7 \mu \mathrm{m}$}

\section{$7 \mu \mathrm{m}$}

Fe Ka1

\section{(C)}
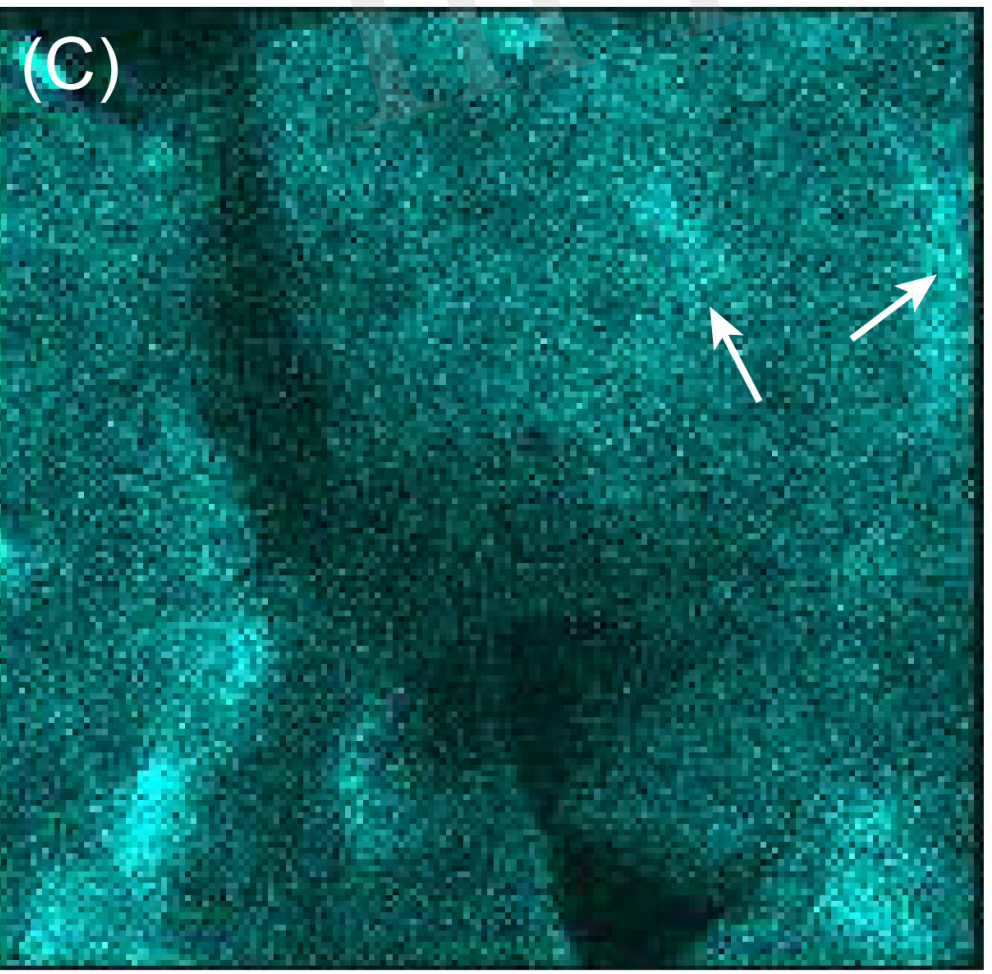

$7 \mu \mathrm{m}$

S Ka1

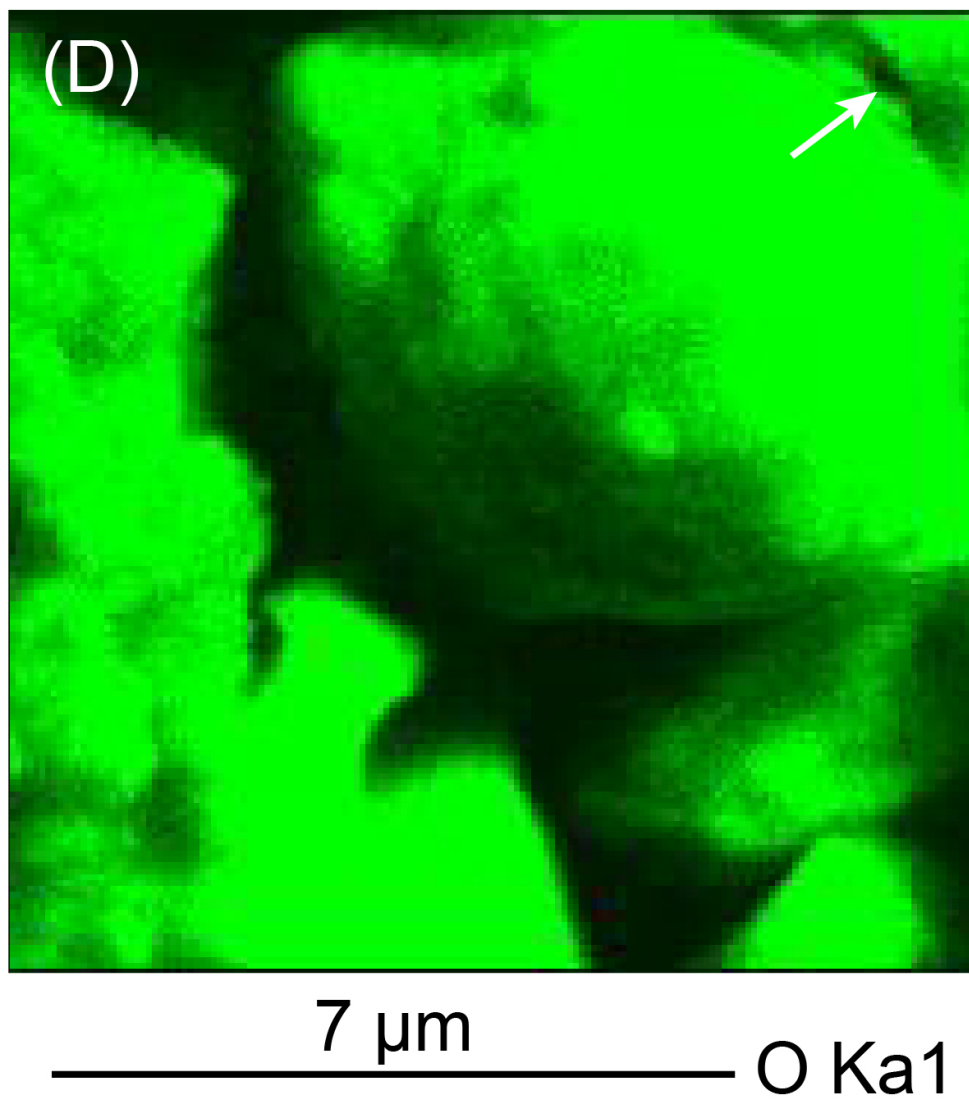


Figure 6.JPEG
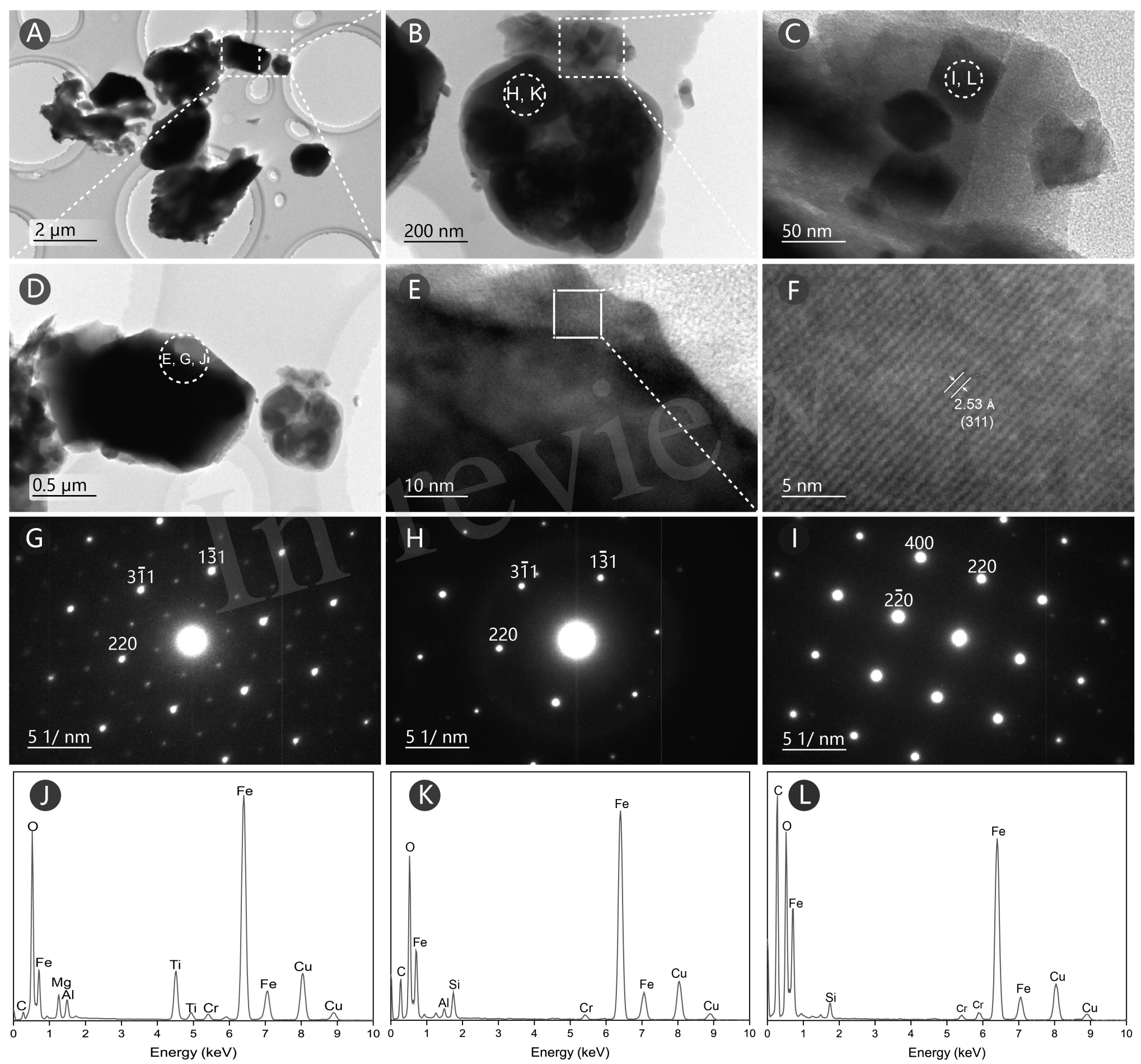

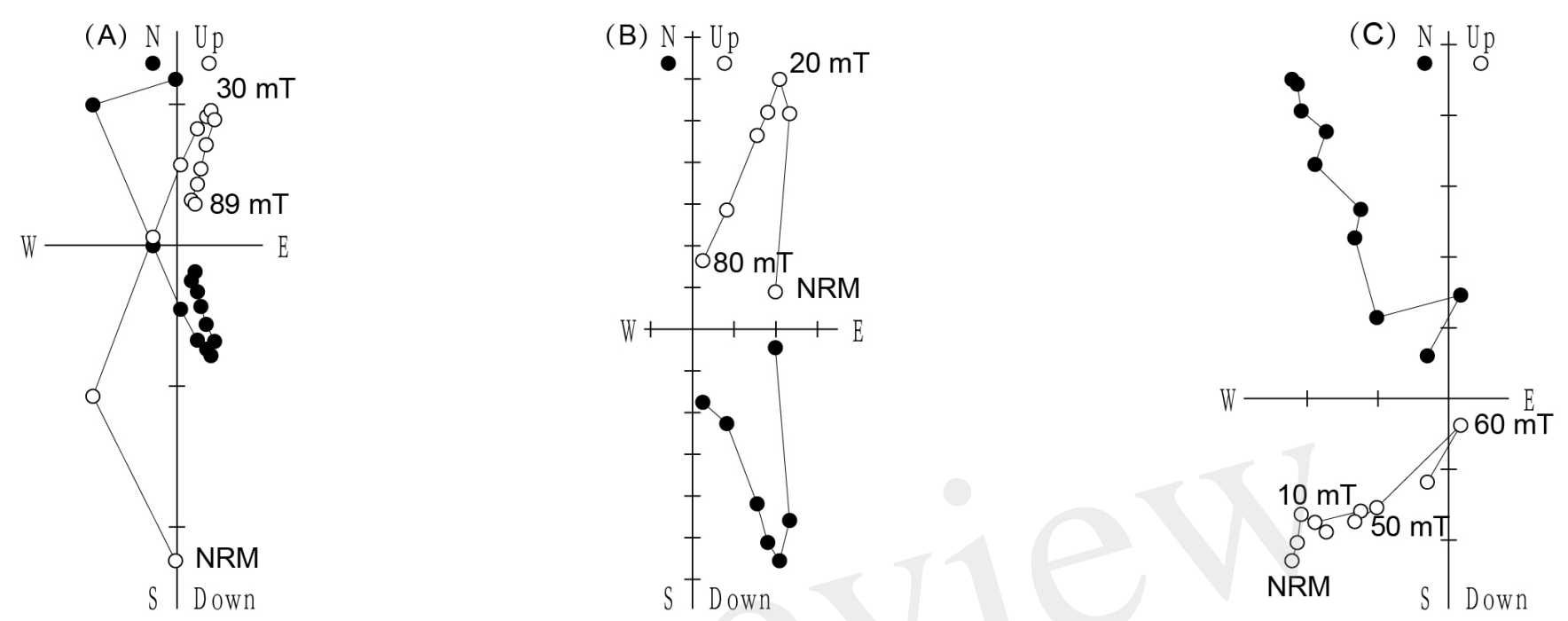

xg $0-3-I S$

Scale: $1 \mathrm{e}-4 \mathrm{~A} / \mathrm{m}$

xg38-3-IS

x g 121-2-I S

Scale: $1 \mathrm{e}-5 \mathrm{~A} / \mathrm{m}$
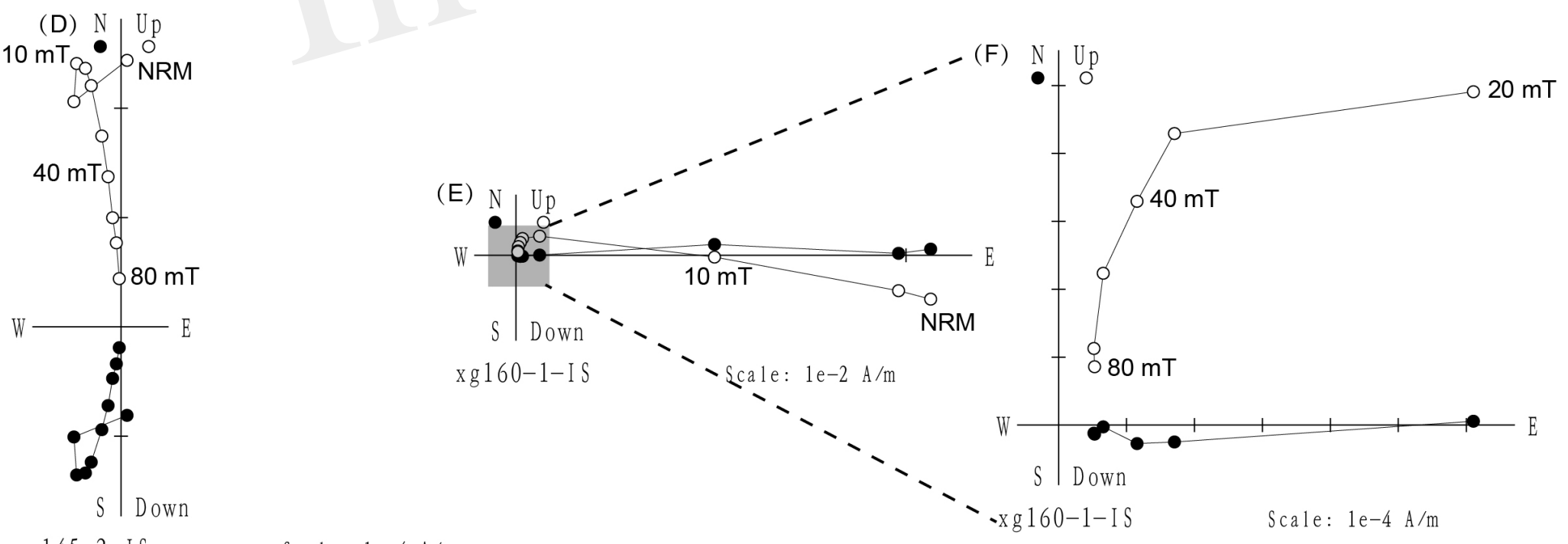

xg 145-2-Is

Scale: $1 \mathrm{e}-4 \mathrm{~A} / \mathrm{m}$ 


\section{Supplementary Material}

\section{$1 \quad$ Supplementary Figures}
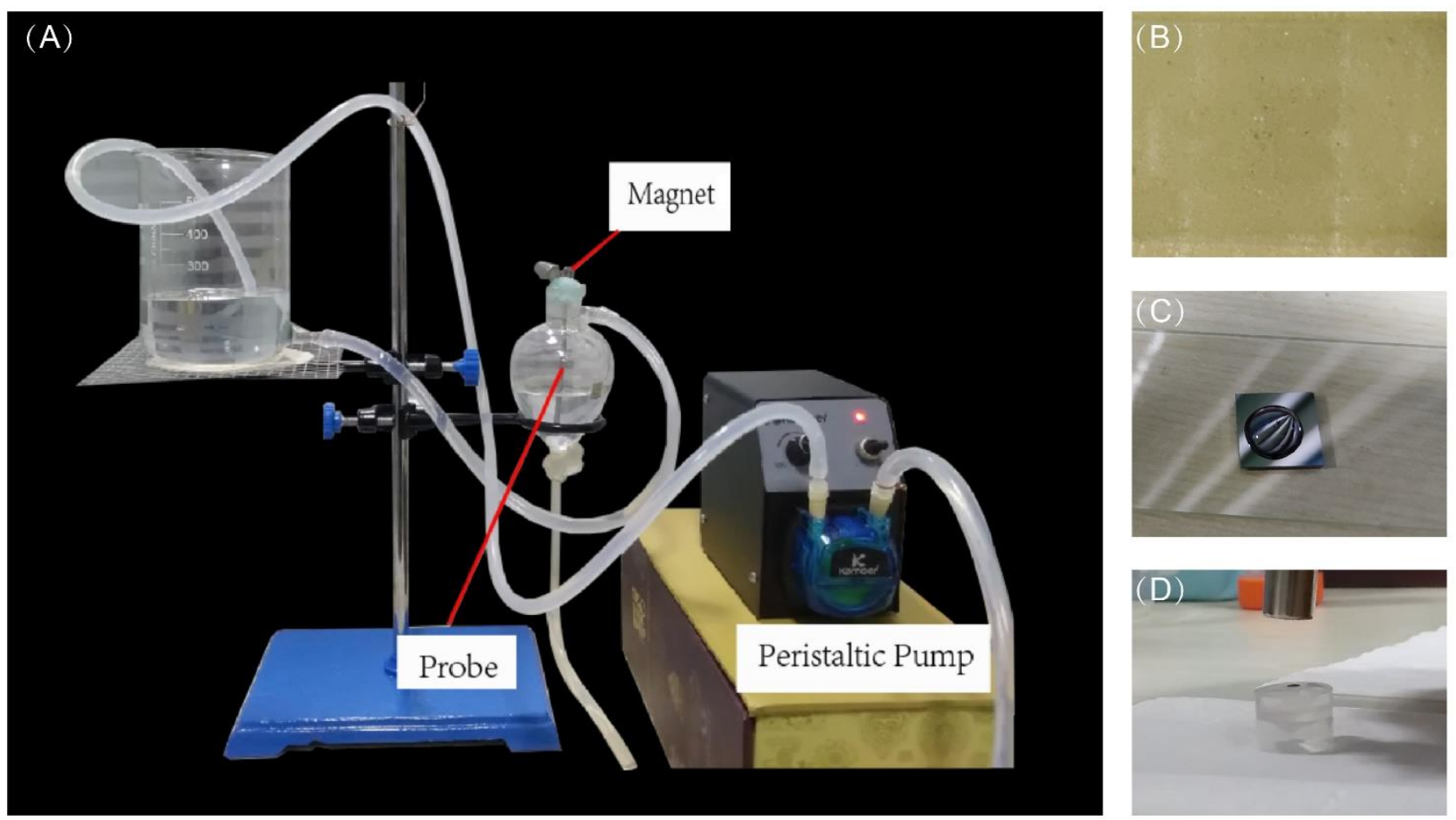

Figure S1. (a) Magnetic extraction apparatus. (b) Samples preparation of thin sections using resin as an adhesive; Magnetic extracts dropping on a monocrystalline silicon wafer (c), and TEM grid (d). 
Supplementary Material
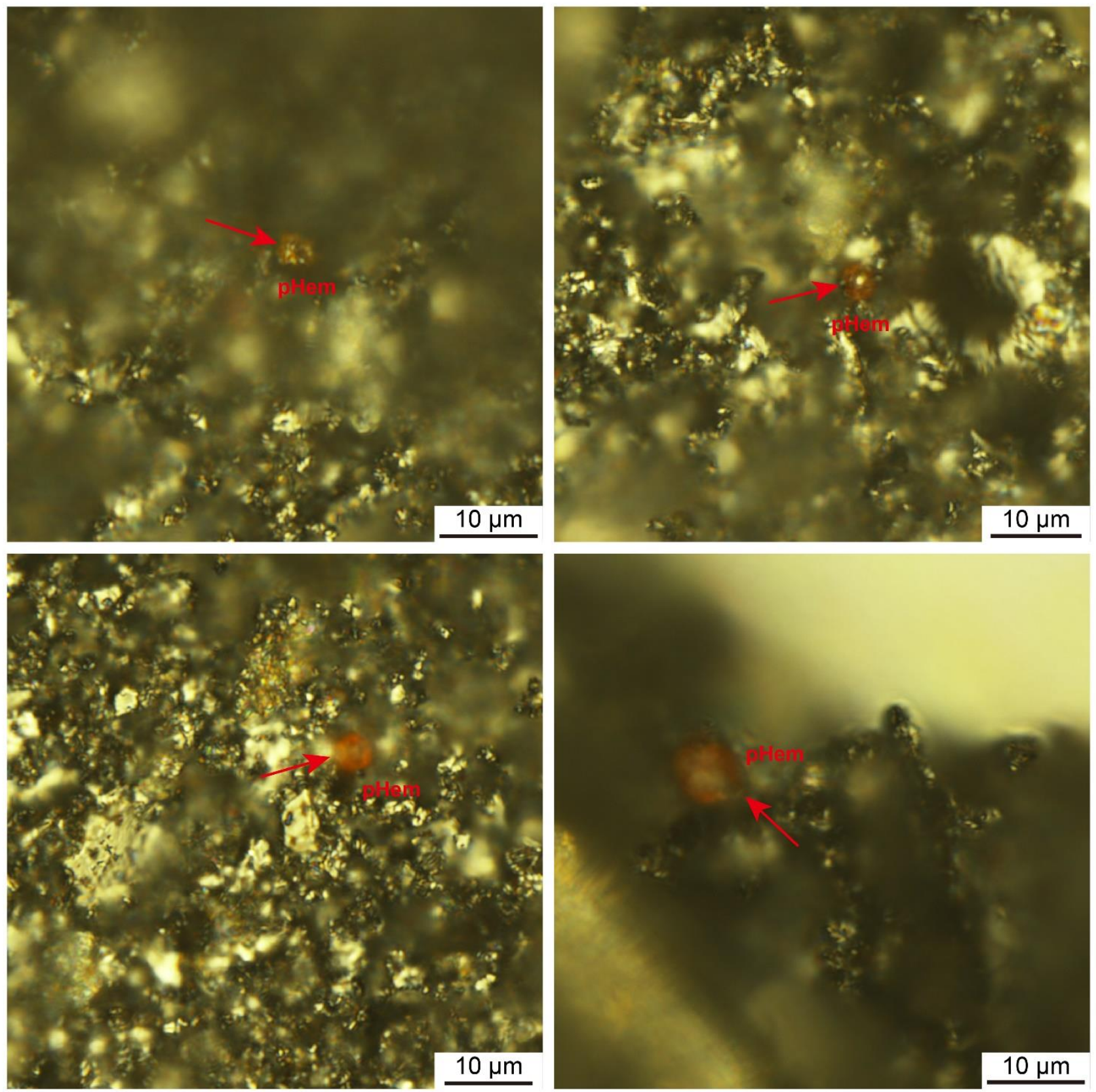

Figure S2. Photomicrographs illustrating the iron oxide spherules of magnetic extracts from the Zongpu carbonate rocks in the Gamba area under reflected light. pHem = pigment hematite. 

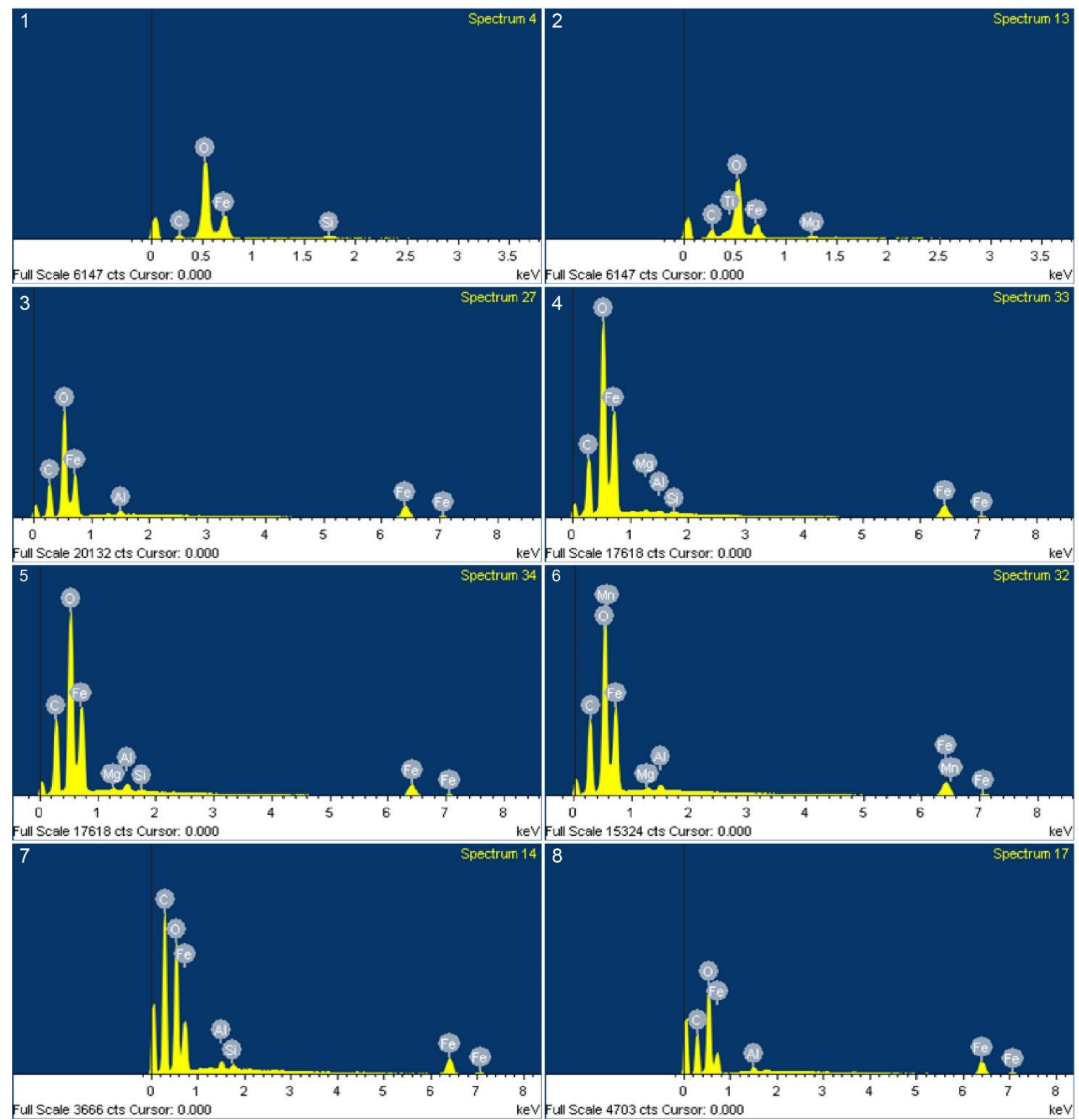

Figure S3. EDS analysis results of the spots shown in Figure 4. 


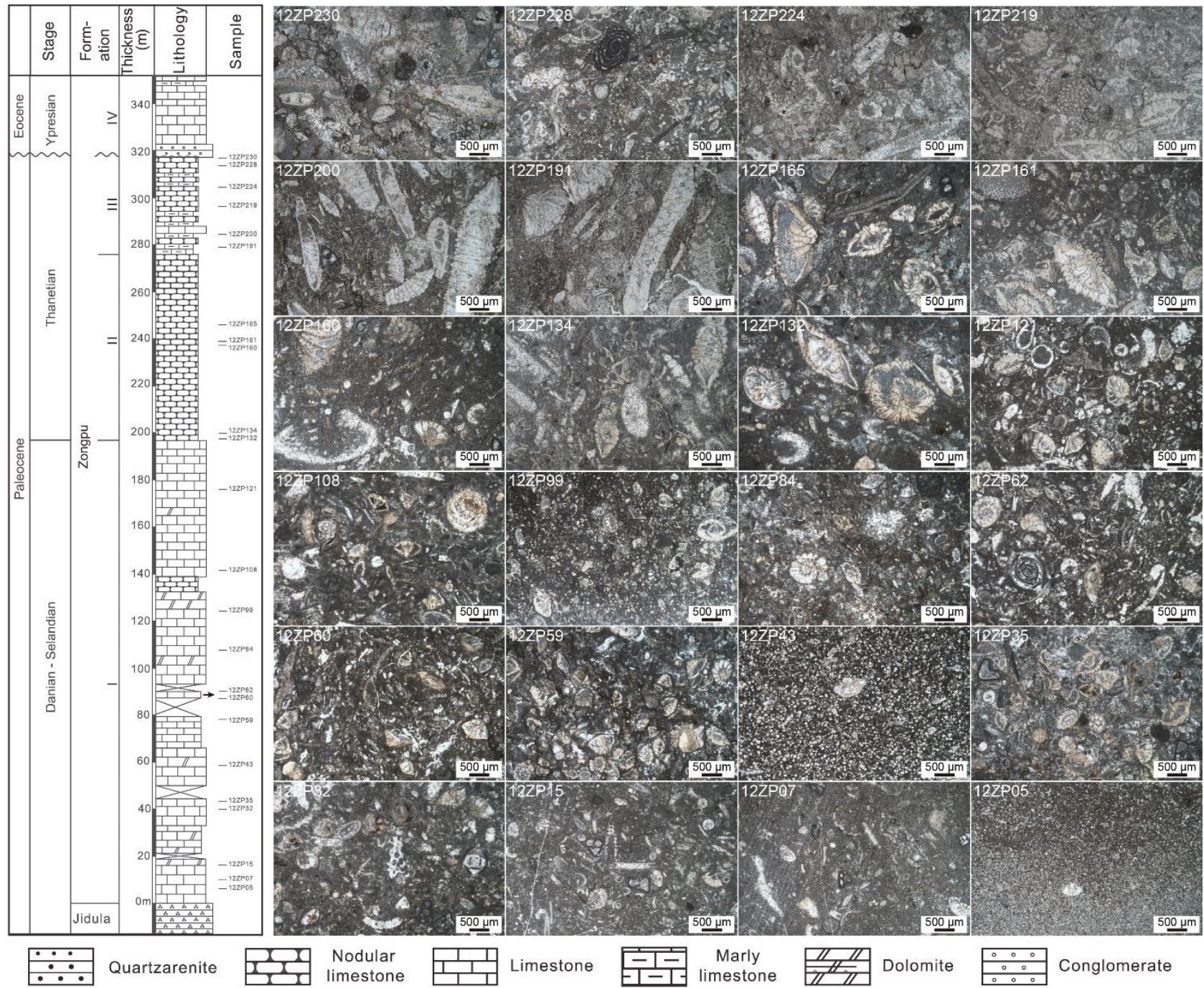

Figure S4. Left: Lithostratigraphy of the Zongpu Formation. Partial sampling localities of rock magnetic measurements in Huang et al. (2017a) were indicated, modified after Li et al. (2015) and Huang et al. (2017a). Right: Corresponding photomicrographs, collected from Li and Hu (2020). Please see www.csdata.org for more micrographs and detailed descriptions. 

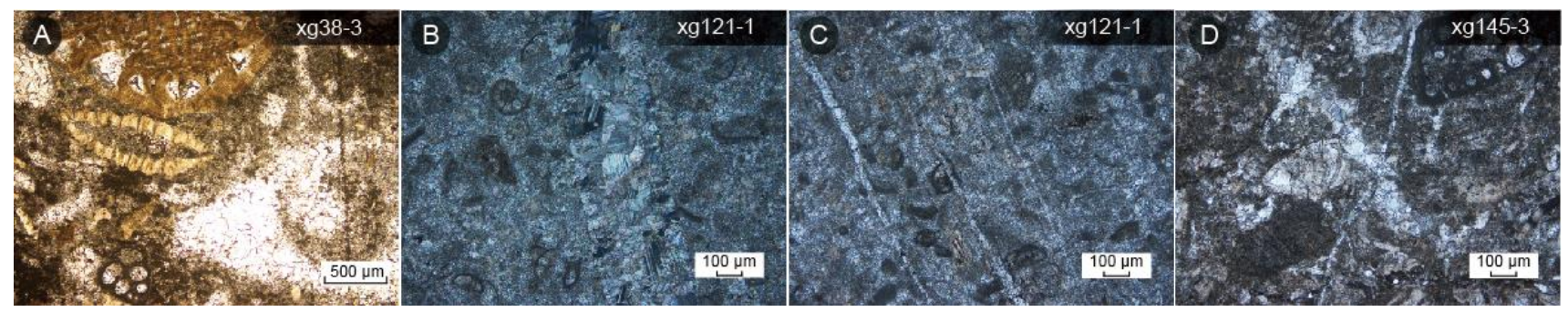

Figure S5. The larger benthic foraminifera from section A of Yi et al. (2011) in plane-polarized light (a) and reflected light (b-d). The localities of sampling collection are marked in Figure 1C.

\section{Reference}

Huang, W., Lippert, P.C., Jackson, M.J., Dekkers, M.J., Zhang, Y., Li, J., et al. (2017a). Remagnetization of the Paleogene Tibetan Himalayan carbonate rocks in the Gamba area: Implications for reconstructing the lower plate in the India-Asia collision. Journal of Geophysical Research-Solid Earth 122(2), 808-825. doi: 10.1002/2016jb013662.

Li, J., Hu, X., Garzanti, E., An, W., and Wang, J. (2015). Paleogene carbonate microfacies and sandstone provenance (Gamba area, South Tibet): Stratigraphic response to initial India-Asia continental collision. Journal of Asian Earth Sciences 104, 39-54. doi: 10.1016/j.jseaes.2014.10.027.

Li, J., and $\mathrm{Hu}, \mathrm{X}$. (2020). A photomicrograph dataset of Late Cretaceous to Early Paleogene carbonate rocks in Tibetan Himalaya. China Scientific Data 5. doi: 10.11922/csdata.2020.0072.zh. 